\title{
Subdural Hematoma Revealing Spontaneous Intracranial Hypotension: Diagnosis and Management. A Report of Four Cases
}

\section{Mounir Ben Ismail}

Department of Neurosurgery, Bretonneau Hospital, 2 Boulevard Tonnelle, 37044 Tours France, France

*Corresponding author: Mounir Ben Ismail, Department of Neurosurgery, Bretonneau Hospital, 2 Boulevard Tonnelle, 37044 Tours France, France, Tel: 0033247474148; E-mail: mounir_ben_ismail@yahoo.fr

Rec date: Dec 11, 2014, Acc date: Jan 24, 2015, Pub date: Jan 26, 2015

Copyright: (c) 2015 Ismail MB. This is an open-access article distributed under the terms of the Creative Commons Attribution License, which permits unrestricted use, distribution, and reproduction in any medium, provided the original author and source are credited.

\begin{abstract}
The subdural hematoma (SDH) could be a serious complication of the spontaneous intracranial hypotension $(\mathrm{SIH})$ that is a rare but well-known entity. We reported four illustrative cases of subdural hematomas revealing SIH. Three women and a man with mean age of 58.5 years. In three cases we noted sudden headaches, progressive and postural in one. CT scan has diagnosed the subdural hematomas that were thin and bilateral in three cases. Magnetic resonance imaging (MRI) confirmed the diagnosis of associated $\mathrm{SIH}$. None has undergone an invasive exploration. Two patients were operated for clinical worsening. All of our patients were treated by epidural lumbar blood patch with very good outcome. author highlights the strategy of diagnosis and management of this underestimated pathology by showing different practical situations.
\end{abstract}

Keywords: Subdural hematoma; Spontaneous intracranial hypotension; Epidural blood patch

\section{Introduction}

Spontaneous intracranial hypotension is a rare but well known clinical entity. It was described first by Schaltenbrand in 1938. This noteworthy clinical syndrome is characterized by postural headaches and may have serious neurological complications as subdural hematomas.

Since last years many cases have been reported in the literature. So far, the actual incidence is still underestimated. The MR Imaging has greatly facilitated the diagnosis and the detection of subdural fluid collections often associated. The subdural hematomas may be inaugural and rarely reveal intracranial hypotension.

We reported four cases of subdural hematoma associated with spontaneous intracranial hypotension and tried to highlight management of this pathology.

\section{Case 1}

A 42-year-old man with no particular medical history or recent trauma, presented for sudden headache in June 2011. The neurological examination was normal. Cranial CT showed a thin bilateral subdural hematoma with no mass effect and slit ventricles. Brain MRI showed an important meningeal enhancement with bilateral subdural hematomas, caudal descent of the tonsils and flattened pons against the clivus. The diagnosis of spontaneous intracranial hypotension was retained and the patient was treated by analgesics and bed rest allowing gradual improvement of the pain.

Three weeks later, headache worsened again with postural character associated to dizziness. CT scan findings were unchanged. So we decided to perform a lumbar epidural blood patch that allowed a good improvement of the symptoms. The patient discharged by day 4 but headache recurred two weeks later. We noted that pain became progressive and lost its orthostatic character and the subdural hematoma has increased on CT. So that, the patient underwent a bilateral twist drill trephination allowing drainage of a high pressure haemorrhagic collection. The symptoms relieved within two days. Check up four months later showed that the patient was not painful and the subdural hematomas disappeared (Figure 1).
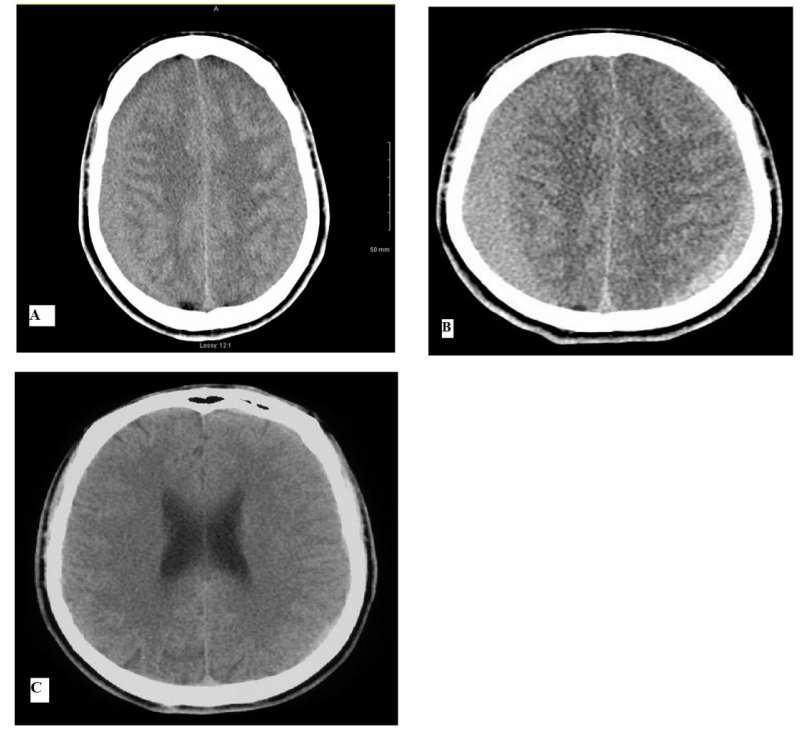

Figure 1: (A) Axial CT scan before the EBP showing bilateral isodense subdural hematoma. (B) Cranial CT scan two weeks after the EBP: the hematomas volume increased. (C) CT scan four months postoperatively: No subdural collection found. 
Citation: Ben Ismail M (2015) Subdural Hematoma Revealing Spontaneous Intracranial Hypotension: Diagnosis and Management. A Report of Four Cases. J Neurol Disord 3: 205. doi:10.4172/2329-6895.1000205

Page 2 of 5

\section{Case 2}

A 60-year-old woman with a history of follicular lymphoma treated by chemotherapy and radiotherapy in November 2003. She was admitted in our department in September 2005 for acute headache, vomiting and tinnitus. She was conscious with no neurological palsy. There was neither a history of head trauma nor haemostasis disturbance. Cranial CT showed a thin left subdural hematoma collection without mass effect and little-sized ventricles.

Brain MRI confirmed the haemorrhagic nature of the collection and showed a pachymeningeal enhancement. The diagnosis of subdural hematoma associated to spontaneous intracranial hypotension was retained and we performed a lumbar epidural patch of $20 \mathrm{ml}$ of Hydroxyethyl starch.

Headaches and other signs disappeared rapidly within two days. She was controlled four months later and she was asymptomatic and the subdural collection disappeared (Figure 2).
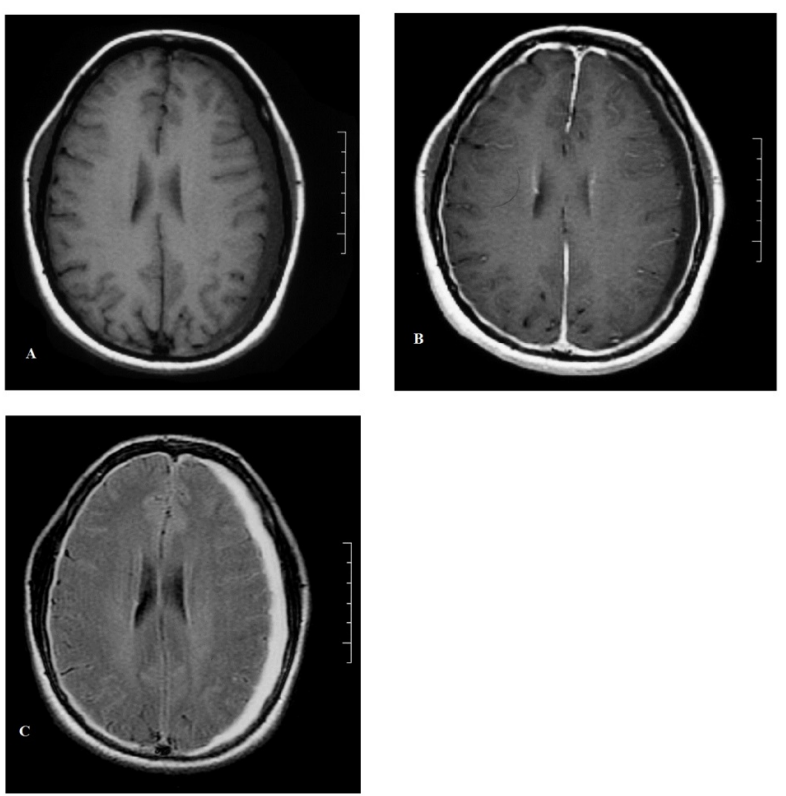

Figure 2: (A) Axial T1W-TSE MR sequence showing slightly hyperintense subdural collection. (B) Axial gadolinium-enhanced T1W-TSE sequence: Notice the diffuse thickening and the strong enhancement of the meninges. (C) Axial FLAIR weighted MR sequence showing left subdural hematoma with slight mass effect and little sized ventricles.

\section{Case 3}

A 57-year-old female with a medical history of mitral regurgitation treated by mechanical valve and vit-K antagonists. She was admitted in our department in November 2009 for sudden headaches and brief consciousness loss. The neurological examination observed no deficit. The CT scan showed a bilateral subdural hematoma and small-sized ventricles.

We suggested a bleeding caused by anticoagulant treatment and we decided a conservative treatment (analgesic, bed rest). Two days later we noted rapidly worsening headache, vomiting and drowsiness. We performed a surgical drainage of the predominant right subdural hematoma. intraoperatively, we noticed a very low evacuation pressure of the haemorrhagic collection. Then an MR imaging was performed and showed a pachymeningeal enhancement and little ventricles, persistent tonsillar herniation, thin perimesensephalic cisterns and residual subdural collection.

We confirmed the diagnosis of spontaneous intracranial hypotension by spinal MR that demonstrated a thoracolumbar CSF leakage. Headache improved partially. We performed a lumbar epidural blood patch and the pain resolved completely. The check-up two months later showed no symptoms and the CT scan was normal (Figure 3).

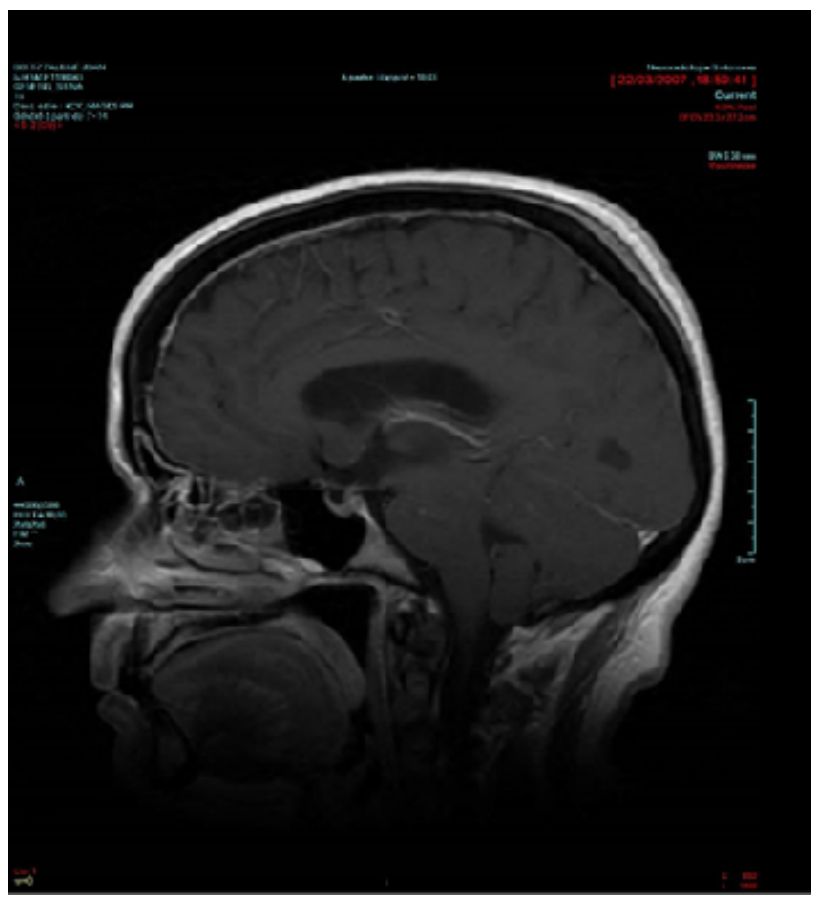

Figure 3: Sagittal Gadolinium TSE T1 weighted MR image: Notice the tonsillar descent, impaction of the pons against the clivus and the effacement of perimesencephalic citerns and the cisterna magna.

\section{Case 4}

A 75-year-old woman with a history of lung lobectomy for tuberculosis. She presented to our department in November 2005 for recent progressive headache and nausea. Anamnesis noticed that the headaches had postural character and worsened by long-lasting upward position associated with tinnitus and dizziness.

The neurological examination showed normal GCS, bilateral pyramidal syndrome and no palsy. Cranial CT pointed out a thin bilateral subdural hematoma, the ventricles were normal without cortical atrophy. The brain MRI showed a diffuse meningeal enhancement, normal-sized ventricles and bilateral subdural hematoma without mass effect. 
Citation: Ben Ismail M (2015) Subdural Hematoma Revealing Spontaneous Intracranial Hypotension: Diagnosis and Management. A Report of Four Cases. J Neurol Disord 3: 205. doi:10.4172/2329-6895.1000205

Page 3 of 5

We performed lumbar epidural blood patch. All the symptoms relieved rapidly. Six months later the check-up showed an asymptomatic patient and the MR imaging noticed the disappearance of the subdural collection and the diffuse enhancement (Figure 4).
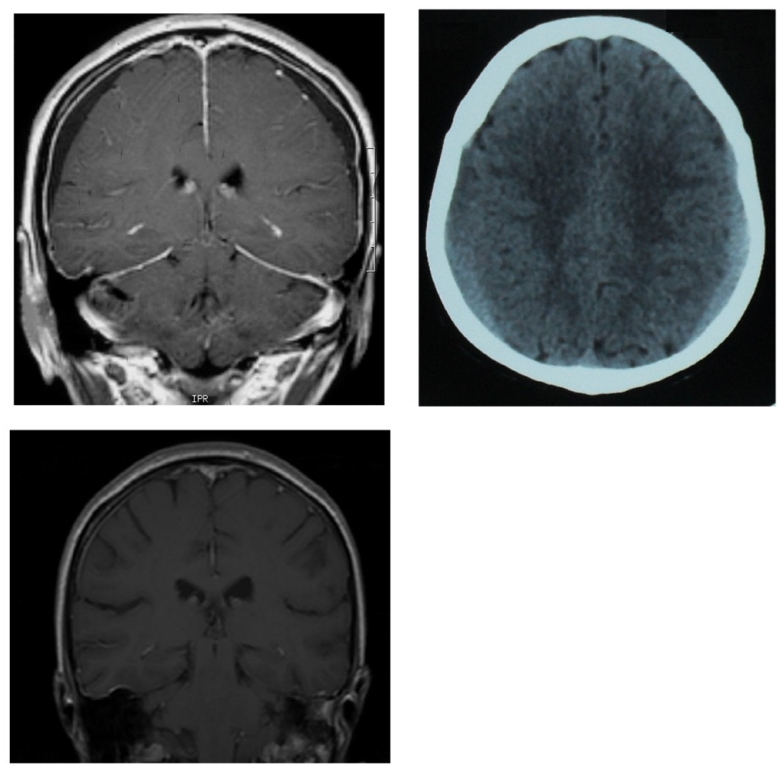

Figure 4: (A) Coronal Gadolinium-enhanced T1W-TSE MR image showing the bilateral subdural hematomas, small ventricles and diffuse meningeal enhancement. (B) Initial cranial CT scan showing a thin bilateral subdural collection. (C) Coronal Gadolinium-enhanced T1W-TSE MR image six months after the EBP: The subdural hematomas and the meningeal thickening disappeared.

The clinicoradiological features of the cases are described in the below mentioned Table 1 .

\begin{tabular}{|l|l|l|l|l|l|}
\hline & $\begin{array}{l}\text { Gender/Ag } \\
\text { e/history }\end{array}$ & Symptoms & Imaging & Treatment & Outcome \\
\hline $\begin{array}{l}\text { Case 1: } \\
\text { (Jun }\end{array}$ & $\begin{array}{l}\text { M 42y } \\
\text { no history }\end{array}$ & $\begin{array}{l}\text { Sudden } \\
\text { headache }\end{array}$ & $\begin{array}{l}\text { CT MRI } \\
\text { Bilateral SDH } \\
\text { and brain } \\
\text { sagging }\end{array}$ & $\begin{array}{l}\text { EBP and } \\
\text { surgical } \\
\text { drainage } \\
\text { (3Weeks } \\
\text { later) }\end{array}$ & Very good \\
\hline $\begin{array}{l}\text { Case 2: } \\
\text { (Sept }\end{array}$ & $\begin{array}{l}\text { F 60y } \\
\text { follicular } \\
\text { lymphoma }\end{array}$ & $\begin{array}{l}\text { Acute } \\
\text { headache, } \\
\text { vomiting }\end{array}$ & $\begin{array}{l}\text { CT MRI left } \\
\text { SDH, } \\
\text { pachymening } \\
\text { itis }\end{array}$ & $\begin{array}{l}\text { Epidural } \\
\text { patch }\end{array}$ & $\begin{array}{l}\text { Relief of } \\
\text { symtoms } \\
\text { by day 2 } \\
\text { Normal CT }\end{array}$ \\
\hline $\begin{array}{l}\text { Case 3: } \\
\text { (Nov } \\
\text { 2009) }\end{array}$ & $\begin{array}{l}\text { F 57y } \\
\text { Vit } \\
\text { antagonists }\end{array}$ & $\begin{array}{l}\text { Krief loss of } \\
\text { headache, } \\
\text { cousciousn } \\
\text { ess }\end{array}$ & $\begin{array}{l}\text { CT bilateral } \\
\text { SDH } \\
\text { Post } \\
\text { operative } \\
\text { MR } \\
\text { meningeal } \\
\text { enhancemen } \\
\text { t and spinal } \\
\text { leak }\end{array}$ & $\begin{array}{l}\text { Surgical } \\
\text { drainage } \\
\text { Post } \\
\text { operative } \\
\text { EBP }\end{array}$ & $\begin{array}{l}\text { Complete } \\
\text { relief after } \\
\text { EBP }\end{array}$ \\
\hline
\end{tabular}

\begin{tabular}{|c|c|c|c|c|c|}
\hline $\begin{array}{l}\text { Case 4: } \\
\text { (Nov } \\
2005 \text { ) }\end{array}$ & $\begin{array}{l}\text { F 75y } \\
\text { history of } \\
\text { Pulmonar } \\
\text { tuberculosi } \\
\text { s }\end{array}$ & $\begin{array}{l}\text { Progressiv } \\
\text { e postural } \\
\text { headache, } \\
\text { tinnitus, } \\
\text { drowsiness }\end{array}$ & $\begin{array}{l}\text { CT MRI } \\
\text { Bilateral SDH } \\
\text { and } \\
\text { meningeal } \\
\text { enhancemen } \\
t\end{array}$ & $\begin{array}{l}\text { "blind " } \\
\text { EBP }\end{array}$ & $\begin{array}{l}\text { Very good } \\
\text { outcome }\end{array}$ \\
\hline
\end{tabular}

Table 1: Clinicoradiological datas, management and outcome of our patients.

\section{Discussion}

Spontaneous intracranial hypotension is an infrequent cause of secondary headache due to cerebrospinal fluid (CSF) hypovolemia. It is a unique medical syndrome that can be revealed by orthostatic headache and which has established criteria in the International Classification of Headache Disorders [1]. This entity was first described by Schaltenbrand in 1938 and initially called "aliquorrhea".

The intracranial hypotension is caused by a spinal cerebrospinal fluid (CSF) leakage and it is considered as spontaneous or idiopathic if there is no evidence of spinal surgery, lumbar puncture or Tarlov spinal cyst $[1,2]$.

The pathophysiology of SIH could be explained by an occult dural tear in the spinal compartment causing CSF leakage and low opening CSF pressure. Many hypotheses were suggested to clear the cause of meningeal dehiscence. A mechanical factor was observed in one third of patients in the literature and predisposition to connective tissue diseases seems to play an important role [2,3]. Meanwhile, the cause of developing subdural haemorrhagic collections remains controversial and still unclear. Two main mechanisms tried to explain bleeding in the subdural space: First, tearing or rupture of bridging veins stretched by low intracranial pressure and the brain downward displacement $[1,3-5]$. Secondly, bleeding and effusion from fragile and dilated dural vessels $[4,6]$.

The existence of subdural hygroma may enlarge the subdural space, stretches moreover the bridging veins and may lead to rupture and then predispose to haemorrhagic collection [7-9].

The actual incidence of this the SIH is underestimated. So far in the literature subdural haematoma is commonly a late finding and occurs in around $10 \%$ of patients with SIH. It seems occurring more frequently in men with a sex ratio 2:1. The onset of symptoms is typically observed between the 4 th and the 5 th decade of life $[1,3,9]$. The mean age of our patients is 58.5 years.

Typically, the clinical syndrome of intracranial hypotension is characterized by postural or orthostatic headache as main symptom probably due to dilatation of cerebral veins and meningeal vessels $[1,9]$.

Headache is often progressive, persistent and improved by bed rest. Postural character is not constant and could be hidden by sudden or progressive worsening of headache or associated consciousness disturbances as we noted in our patients [2].

Other clinical features may be associated including visual disturbances, occurring in $23 \%$ of patients, as visual acuity loss and field deficit, nystagmus, photophobia and oculomotor cranial nerves palsies explained by distortion of optic chiasm, compression or vascular congestion of the optic and ocular motor nerves $[1,10]$. Also auditory or vestibular symptoms including hypo or hyperacousis, tinnitus, nausea, vomiting and dizziness were observed in about $20 \%$ 
of patients and resulting probably from a low intralabyrinthine pressure $[2,10]$.

The onset of the symptoms is often progressive. Rapid worsening or sudden onset may herald SDH and hide the insidious associated signs, in such cases it could considered as inaugural entity of the SIH syndrome.

Neurological deficit and consciousness trouble were reported in some cases. This status could be related to brain venous thrombosis, hindbrain herniation and $\mathrm{SDH}$, may cause misdiagnosis of associated intracranial hypotension [1,4,10-14].

The CT scan is the frontline imaging workup for headache, excepted the presence of the subdural hematoma, this exam can be easily interpreted as being unremarkable. However, subtle signs may suggest the diagnosis of associated SIH; small-sized lateral ventricles, tightness of basal cisterns and cortical sulci showing the paucity of CSF especially for the age. The SDH appears usually thin hyper or isodense comparing to the brain density and may be uni or bilateral, asymmetrical. Its mass effect is usually moderate $[15,16]$.

The advent of MR imaging of the brain has revolutionized the vision of the intracranial hypotension showing many features well described in the literature. These MR findings are mainly attributed to CSF hypovolaemia, brain sagging and secondary reactive changes. The most characteristic feature is the diffuse thickening of the meninges and the strong meningeal post gadolinium enhancement first described in 1991 and mainly explained by the dilatation of the meningeal vasculature. Venous distension sign may be seen in the middle part of the transverse sinus and in the sagittal sinus, and venous engorgement of the pituitary and the dura cross the sella turcica $[1,17,18]$. Other signs including decreased dimension of the suprasellar cistern, bowing of optic chiasma, flattening of the pons against the clivus and effacement of the perimesencephalic cistern are observed. The ventricles are commonly thin or even slit. Further features as pons flattening against the clivus, caudal displacement of the cerebellar tonsils and the diencephalon and downward traction and distorsion of cranial nerves are related to brain sagging $[1,2,9,10,13,17,19-21]$.

Subdural fluid collections are frequently noted in MR imaging and their incidence widely varied from 10 to $69 \%$, merely $20 \%$ of them are haemorrhagic $[18,20,22,23]$.

These subdural hematomas show high signal intensity on T1 and T2-weighted images with moderate thickness and very mild mass effect as reported in our patients $[15,16]$.

These MR findings could be characteristic and may obviate the need of lumbar tap to depict the typical low CSF pressure. Especially when SDH is already illustrated, the lumbar tap is not recommended as it could worsen the intracranial hypotension.

The first difficulty that the clinician would confront in managing these subdural hematomas is to consider their causal relationship with an intracranial hypotension. The features described previously should draw his attention to this possibility and urge to perform a brain MRI.

Seeking for the spinal CSF leak needs further specific investigation imaging. The MRI cisternography seems to be more accurate than the CT myelography in detecting CSF outside spinal axis. Computed tomography myelography and radionuclide cisternography appears more specific and visualise the extrathecal contrast or tracer activity.
However, these radiological exams appear as invasive and timeconsuming, with negative or nonspecific findings in about 30\% [10].

When the diagnosis of associated intracranial hypotension is established, the management of the subdural hematomas depends first on clinical status of the patient. Conservative symptomatic treatment and bed rest are required and can be efficient within few days.

The EBP is nowadays the treatment of choice of the intracranial hypotension. The mechanism of action is unknown and controversial. It aims to plug the potential spinal meningeal gap and seal the CSF leakage and therefore to stop the extension of the subdural collection [6]. Its reported overall success rate for headache improvement is $30 \%$ to $70 \%$ after the first attempt and success rate of $85 \%$ in reverting patients who were comatose due to SIH $[24,25]$.

This patch consists on injecting 20 to $30 \mathrm{cc}$ of autologus blood in the lumbar epidural space. The efficiency of this lumbar patch has been admitted in all spinal location of leakage. Many previous reports have established the efficiency of "blind" EBP as injected blood spreads over many vertebral segments $[6,23,25]$. Other authors, recommended the EBP even before causal research when the clinical and radiological features are suggestive $[26,27]$.

As the subdural hematoma is a serious complication of the intracranial hypotension and the lumbar EBP is efficient in the majority of the reported cases, we propose performing this procedure as early as possible without need to perform further exams for seeking the spinal leakage. This is in order to give rapid relief of symptoms and avoid the risk of neurological worsening.

The timing of active surgical drainage is still controversial; it is advised in case of severe resistant headache, consciousness disturbance and or neurological palsies, collection thick superior to $1 \mathrm{~cm}$. The drainage is required as first step to restore some intracranial tension equilibrium expecting curative EBP necessary to increase CSF volume and avoid recurrence. Usually, the surgical intervention allows rectifying an initial misdiagnosis by showing a low pressure evacuation of the haemorrhagic subdural collection as described in our patient $\mathrm{N}^{\circ}$ 3. A special care is needed while deciding the surgical drainage, the diagnosis of intracranial hypotension should be previously evoked because it could worsen the pressure gradient between intracranial and intra spinal compartments, the downward shift of the brain with buckling of brain stem and may decrease the buoyant effect of CSF in keeping the brain afloat more, subsequently, caudal herniation and buckling of brain stem deteriorate the clinical status postoperatively $[28,29]$.

As observed in our patient $\mathrm{N}^{\circ} 1$, rarely, the SDH could worsen independently and progress in spite of local efficiency of the EBP. In this case, surgical evacuation is required as in common subdural hematoma.

Noticing the very good results obtained in our patients and the high rate of efficiency reported in the literature and based on suggestive clinicoradiological features and the absence of related medical history, we suggest that treating these patients by early and "blind" EBP could be an interesting option in managing subdural hematomas associated with spontaneous intracranial hypotension. We think that additional investigations as CT Myelography or radionuclide cisternography to confirm the CSF leak and its anatomic location should be reserved for the cases of inefficiency of EBP [27]. 
Citation: Ben Ismail M (2015) Subdural Hematoma Revealing Spontaneous Intracranial Hypotension: Diagnosis and Management. A Report of Four Cases. J Neurol Disord 3: 205. doi:10.4172/2329-6895.1000205

Page 5 of 5

\section{Conclusion}

The subdural hematoma may be a serious complication of spontaneous intracranial hypotension and can be inaugural. However, this pathology remains underestimated and often misdiagnosed. The clinician should pay attention and think about this association especially when the subdural hematoma is thin, bilateral without history of head trauma. Seeking postural character of headaches and performing MR imaging to approach the diagnosis. Blind epidural blood patch is the first treatment of choice. Recourse to surgical treatment should be reserved to poor neurological status.

\section{References}

1. Haritanti A, Karacostas D, Drevelengas A, Kanellopoulos V, Paraskevopoulou E, et al. (2009) Spontaneous intracranial hypotension: clinical and neuroimaging findings in six cases with literature review. Eur J Radiol 69: 253-259.

2. Shima K, Ishihara S, Tomura S (2008) Pathophysiology and diagnosis of spontaneous intracranial hypotension. Acta Neurochir Suppl 102: 153-156.

3. Blank SC, Shakir RA, Bindoff LA, Bradey N (1997) Spontaneous intracranial hypotension: clinical and magnetic resonance imaging characteristics. Clin Neurol Neurosurg 99: 199-204.

4. Hejazi N, Al-Witry M, Witzmann A (2002) Bilateral subdural effusion and cerebral displacement associated with spontaneous intracranial hypotension: diagnostic and management strategies. Report of two cases. J Neurosurg 96: 956-959.

5. Augustin J, Proust F, Verdure L, Langlois O, Freger P (2003) [Bilateral chronic subdural hematoma: spontaneous intracranial hypotension? Neurochirurgie 49: 47-50.

6. Praline J, Cottier JP, Aesch B, Herbreteau D, Jan M (2003) [Image-guided epidural blood patch as effective treatment of intracranial hypotension. A case report]. Neurochirurgie 49: 51-54.

7. Sato Y, Honda Y, Maruoka H, Fujimatsu Y, Oizumi K (1997) Recurrence of spontaneous intracranial hypotension with subdural hematomas. Cephalalgia 17: 42-45.

8. Evan RW, Mokri B (2002) Spontaneous intracranial hypotension resulting in coma. Headache 42: 159-160.

9. Mokri B, Posner JB (2000) Spontaneous intracranial hypotension: the broadening clinical and imaging spectrum of CSF leaks. Neurology 55: 1771-1772.

10. Mokri B (2014) Spontaneous CSF leaks: low CSF volume syndromes. Neurol Clin 32: 397-422.

11. de Noronha RJ, Sharrack B, Hadjivassiliou M, Romanowski CA (2003) Subdural haematoma: a potentially serious consequence of spontaneous intracranial hypotension. J Neurol Neurosurg Psychiatry 74: 752-755.

12. Crocker M, Choo M, Rich P, Martin AJ (2008) Avoiding the drill: Intracranial hypotension presenting with subdural hematoma. Injury Extra 39: 287-290.
13. Sayer FT, Bodelsson M, Larsson EM, Romner B (2006) Spontaneous intracranial hypotension resulting in coma: case report. Neurosurgery 59: E204.

14. Paldino M, Mogilner AY, Tenner MS (2003) Intracranial hypotension syndrome: a comprehensive review. Neurosurg Focus 15: ECP2.

15. Park ES, Kim E (2009) Spontaneous intracranial hypotension: clinical presentation, imaging features and treatment.J Korean Neurosurg Soc 45: $1-4$.

16. Schievink WI, Maya MM, Louy C, Moser FG, Tourje J (2008) Diagnostic criteria for spontaneous spinal CSF leaks and intracranial hypotension. AJNR Am J Neuroradiol 29: 853-856.

17. Albayram S, Kilic F, Ozer H, Baghaki S, Kocer N, et al. (2008) Gadolinium-enhanced MR cisternography to evaluate dural leaks in intracranial hypotension syndrome. AJNR Am J Neuroradiol 29: 116-121.

18. Matsumura A, Anno I, Nose T, Fujimoto A, Shibata Y, et al. (2001) Intracranial hypotension. J Neurosurg 95: 914-916.

19. Nakajima H, Sakai T, Aoki N, Takakura K (1996) Bilateral chronic subdural hematomas associated with intracranial hypotension--case report. Neurol Med Chir (Tokyo) 36: 647-649.

20. Lai TH, Fuh JL, Lirng JF, Tsai PH, Wang SJ (2007) Subdural haematoma in patients with spontaneous intracranial hypotension. Cephalalgia 27: 133-138.

21. Mamelak AN, Fishman RA, Dillon WP, Wilson CB (1996) Spontaneous intracranial hypotension. J Neurosurg 85: 192-193.

22. Mokri B (2001) The Monro-Kellie hypothesis: applications in CSF volume depletion. Neurology 56: 1746-1748.

23. Cohen A, Jesuthasan M (2004) 'Blind' epidural blood patch for spontaneous intracranial hypotension. Anaesthesia 59: 190-191.

24. Zada G, Pezeshkian P, Giannotta S (2007) Spontaneous intracranial hypotension and immediate improvement following epidural blood patch placement demonstrated by intracranial pressure monitoring. Case report. J Neurosurg 106: 1089-1090.

25. Lee GK, Abrigo JM, Cheung TC, Siu DY, Chan DT (2014) Spontaneous intracranial hypotension: improving recognition and treatment strategies in the local setting. Hong Kong Med J 20: 537-540.

26. Su CS, Lan MY, Chang YY, Lin WC, Liu KT (2009) Clinical features, neuroimaging and treatment of spontaneous intracranial hypotension and magnetic resonance imaging evidence of blind epidural blood patch. Eur Neurol 61: 301-307.

27. Hyun SH, Lee KH, Lee SJ, Cho YS, Lee EJ, et al. (2008) Potential value of radionuclide cisternography in diagnosis and management planning of spontaneous intracranial hypotension. Clin Neurol Neurosurg 110: 657-661.

28. Dhillon AK, Rabinstein AA, Wijdicks EF (2010) Coma from worsening spontaneous intracranial hypotension after subdural hematoma evacuation. Neurocrit Care 12: 390-394.

29. Chotai S, Kim JH, Kim JH, Kwon TH (2013) Brain herniation induced by drainage of subdural hematoma in spontaneous intracranial hypotension. Asian J Neurosurg 8: 112-115. 